\title{
Simulation of ISFET operation based on the site-binding model
}

\author{
L. K. Meixner and S. Koch \\ Lehrstuhl für Integrierte Schaltungen der Technischen Universität München, Arcisstrasse 21, W-8000 Munich 2 (FRG)
}

\begin{abstract}
A program for the simulation of the response of an ISFET with an oxynitride gateinsulator will be introduced, which is based on the site-binding model and is designed for an ISFET working in constant charge mode. With this program, principal properties of ISFET operation can be calculated, such as $\mathrm{pH}$ sensitivity dependent on surface charge density and surface composition. In addition, an ISFET for the detection of protein charges can be simulated. The major result for this device is that the better the ISFET works as a pH sensor, the worse it performs as an immuno-FET.
\end{abstract}

\section{Introduction}

Many efforts have been made to realize the direct detection of protein charges with the ISFET since 1975, when Janata [1] introduced this sensor in literature. But up to now, no research group has achieved promising experimental results which show that this device, the so-called immuno-FET, is feasible. Our own investigations in the field of immuno-FET led to a simulation program [2] for ISFETs. The program is based on the site-binding model, which is used by many authors to explain ISFET operation. The implementation of this model is done without simplifications (the inner Helmholtz plane (IHP) is also taken in consideration) and the formulas are used in their most original form. The first version of the program gives the response of an ISFET with oxynitride gateinsulator operated at a constant charge mode to $\mathrm{pH}$ and salt concentration of the electrolyte. To assess the behaviour of an immuno-FET, additional changes were introduced in the IHP which imitate the characteristics of protein charges.

\section{The site-binding model}

This model was introduced in 1973 by Yates $e t$ al. [3] to describe the properties of an oxide aqueous electrolyte interface and was generalized in 1986 by Fung et al. [4] to characterize ISFETs with oxide gateinsulators. It is founded on the thermodynamical fundamentals of the equilibrium reactions of the surface groups and the GouyChapman-Stern theory of the ion distribution at an electrolyte-solid interface. Figure 1 shows the particle, charge and potential distribution according to this model at an electrolyte-ISFET structure. The charge directly at the solid surface is generated by ionization of surface groups due to their acid-base equilibrium reaction with the $\mathrm{H}^{+}$ ions of the electrolyte [5]. It is dependent on the

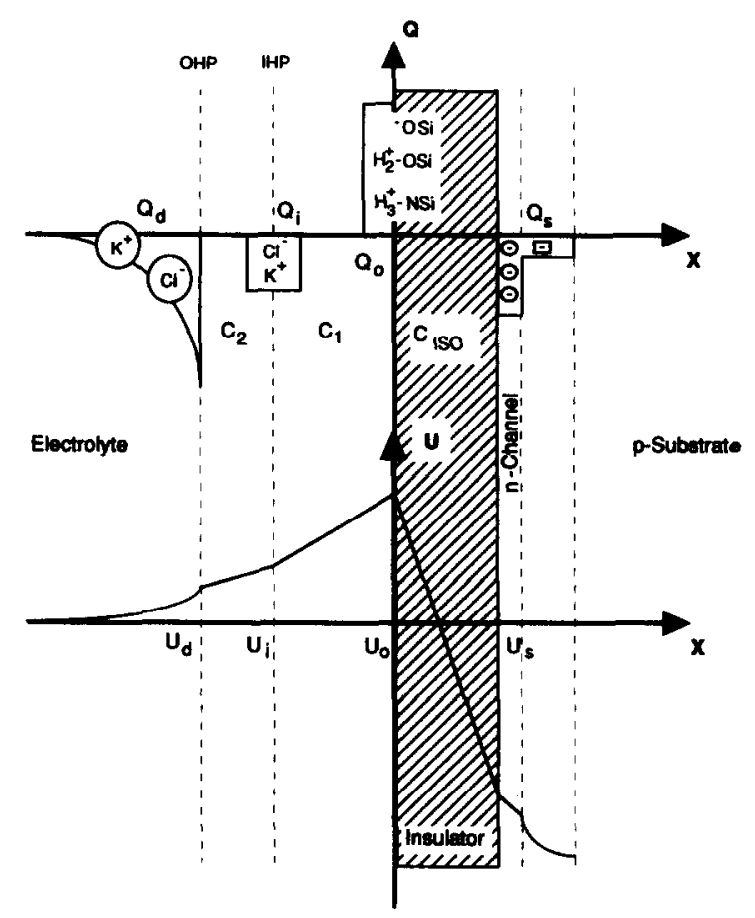

Fig. 1. Particle, charge and potential distribution of an ISFET for $\mathrm{pH}<\mathrm{pH}_{\mathrm{pzc}}$. 
concentration of the $\mathrm{H}^{+}$ions in the bulk of the electrolyte and the electrical potential at the surface. For the whole structure charge neutrality has to be postulated; this implies that the surface charge is compensated by oppositely charged ions in the inner Helmholtz plain (IHP), in the zone from the outer Helmholtz plain (OHP) to the bulk of the electrolyte and the channel charge. The arrangement of the ions from the surface to the bulk of the electrolyte determines the potential at the surface in dependence on the concentration of the electrolyte and the surface charge. Therefore the surface potential depends on the composition of the electrolyte as well as on the properties of the surface groups.

For these models ISFETs with a silicon nitride gateinsulator have been used; therefore mainly $\mathrm{SiOH}$ and $\mathrm{SiNH}_{2}$ groups have to be taken into consideration [6]. For simplicity other groups (such as secondary amines) were neglected in these simulations.

The equations used in the simulation program, that is the dissociation equilibria of the abovementioned surface groups and of the supporting electrolyte, as well as the equations for charge, potential and capacitances, were formulated in accordance to Fung [4] and can be studied there in detail.

\section{The protein charges}

Proteins are large molecules which are composed of chains of amino acids ( $>30$ amino acids). Amino acids are organic molecules with at least one $\mathrm{NH}_{2}$ and one $\mathrm{COOH}$ group, which can form long chains via so-called peptide-bonds between the $\mathrm{NH}_{2}$ group from one molecule and the $\mathrm{COOH}$ group from another. So most of these acid and base groups are used to form these peptidebonds and only a few amino acids with free additional functional groups can carry charges. The maximum number of charges per protein molecule is given by the number of amino acids at the end of the chains and the number of some special amino acids with additional functional groups (e.g., histidine, lysine, aspartic acid) [7].

The mechanism of these acid-base reactions can be described by analogue equations involving the surface groups and the electrolyte ions. In general, the ionization of an acid can be described by eqn.
(1) and of a base by eqn. (2).

$$
\begin{aligned}
& \frac{\left[\mathrm{A}^{-}\right]\left[\mathrm{H}^{+}\right]}{[\mathrm{AH}]} \exp \left(-\frac{\mathrm{e}_{0} \mathrm{U}}{\mathrm{k}_{\mathrm{B}} \mathrm{T}}\right)=\mathrm{K}_{\mathrm{A}} \\
& \frac{[\mathrm{B}]\left[\mathrm{H}^{+}\right]}{\left[\mathrm{BH}^{+}\right]} \exp \left(-\frac{\mathrm{e}_{0} \mathrm{U}}{\mathrm{k}_{\mathrm{B}} \mathrm{T}}\right)=\mathrm{K}_{\mathrm{B}}
\end{aligned}
$$

If the composition of a protein molecule and the values of the dissociation and protonation constants for all functional groups are known, one can get an approximate estimation of the behaviour of the protein charges. This estimation is an upper limit for the protein charge, because the adsorption of oppositely charged so-called counter ions from the electrolyte is not taken into account.

\section{The program}

The program works according to the flow chart in Fig. 2. It is running on an IBM PC compatible computer with coprocessor and was written in Turbo Pascal 5.5. For the simulation of an immunoFET the additional charges described in the last Section were added to the charges of the IHP. This is, of course, a non-realistic place for these charges,

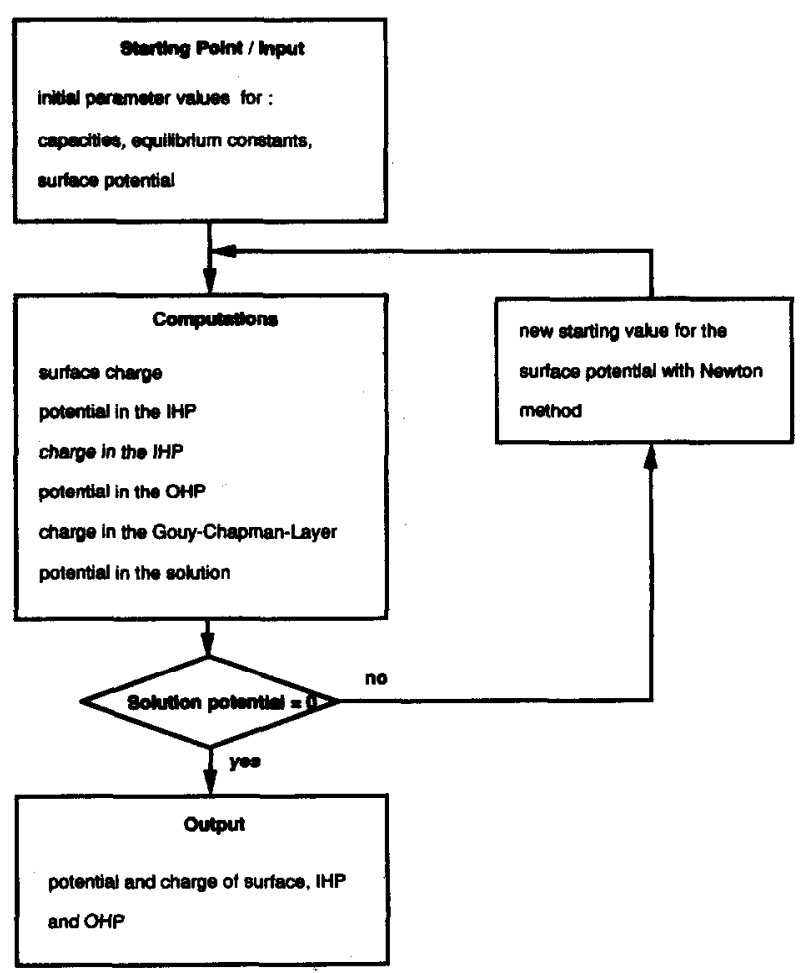

Fig. 2. Flow chart of the simulation program for a pH-ISFET. 
but according to simple models for the potential development of proteins [8] it should be the best place for the greatest effect on the ISFET signal.

\section{Results}

In this program typical values from Fung [4], Harame [9], and Barabash [10] were used for the various parameters. If nothing else is indicated, the following values are used for the simulation of an ISFET: $C_{1}=100 \mathrm{nF} / \mathrm{cm}^{2}$, $\mathrm{C}_{2}=20 \mathrm{nF} / \mathrm{cm}^{2}, \mathrm{C}_{\text {iso }}=520 \mathrm{nF} / \mathrm{cm}^{2}, \mathrm{Q}_{\mathrm{s}}=-5.83 \times$ $10^{-8} \mathrm{Cb} / \mathrm{cm}^{2}, \mathrm{~K}_{1}=3.16 \times 10^{-7}, \mathrm{~K}_{2}=31.6, \mathrm{~K}_{3}=$ $10^{-10}, \quad K_{11}=K_{22}=K_{33}=0.32$, the unit for all $\mathrm{K}_{i}$ is $\mathrm{mol} / \mathrm{l}$, for $\mathrm{SiO}_{2}: \mathrm{n}_{\text {tot }}=5 \times 10^{14} \mathrm{~cm}^{-2}$, for $\mathrm{Si}_{3} \mathrm{~N}_{4}: \mathrm{n}_{\mathrm{tot}}=5 \times 10^{14} \mathrm{~cm}^{-2}=\mathrm{n}_{\mathrm{SiO}_{2}}+\mathrm{n}_{\mathrm{Si}_{3} \mathrm{~N}_{4}}, \mathrm{n}_{\mathrm{SiO}_{2}} /$ $\mathrm{n}_{\mathrm{Si}_{3} \mathrm{~N}_{4}}=2 / 3$, ionic strength $=0.1 \mathrm{~mol} / 1$.

For the protein the values of Streptavidin, a protein with 159 amino acids, are used. It is assumed that the following special amino acids are in each molecule: 36 aspartic acid with $\mathrm{pK}=3.5$ (in short Asp 36, pK = 3.5); His 8, pK = 5.45; Tyr 24, $\mathrm{pK}=9.6 ;$ Lys 16, pK $=9.4 ;$ Arg 16, pK $=12.5$ with a density of $\mathrm{n}_{\text {prot }}=10^{12} \mathrm{~cm}^{-2}$ molecules at the sensor [2].

First the program was used to simulate the $\mathrm{pH}$ response of an ISFET. Figure 3 shows the surface potential versus $\mathrm{pH}$ curves of an ISFET with different ratios of silanol to amino groups from $100 \%$ silanol to $100 \%$ amino groups. It is obvious that the more amino groups are present on the surface, the higher the potential and the value of the point of zero charge $\left(\mathrm{pH}_{\mathrm{pzc}}\right)$ will be. Just the same is observed in experiments, where $\mathrm{SiO}_{2}$ has a $\mathrm{pH}_{\mathrm{pzc}}$ of $\mathrm{pH}$ 2-3 [11], for $\mathrm{Si}_{3} \mathrm{~N}_{4}$ sensors it is assumed to be at pH 5-6 [9].

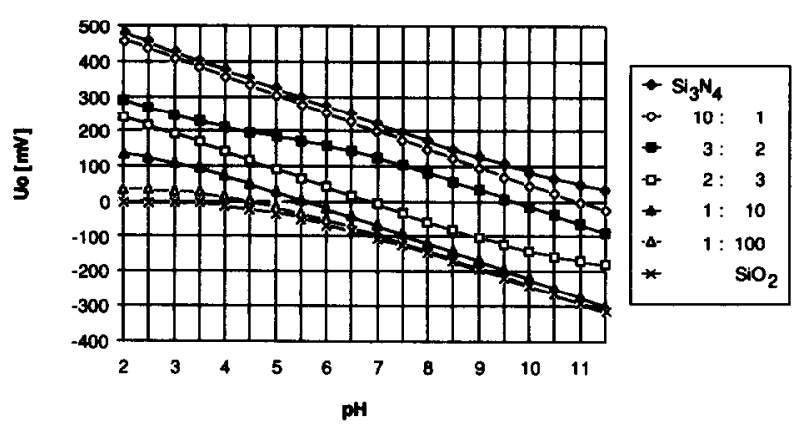

Fig. 3. Potential-pH curves for ISFETs with variable surface composition (total surface group density: $5 \times 10^{14} \mathrm{~cm}^{-2}$ ).
Figure 4 gives the potential-pH curves for different surface group densities. This Figure shows that this parameter is the most significant one for the $\mathrm{pH}$ sensitivity. The lower the surface group density, the lower the $\mathrm{pH}$ sensitivity. The $\mathrm{pH}$ sensitivity seems to tend towards an upper limit in the order of the Nernst sensitivity.

If one extends the typical $\mathrm{pH}$ range $(\mathrm{pH} 2-10)$ for the simulation to the range $\mathrm{pH}-30$ to $\mathrm{pH} 30$, the full shape of the curve can be obtained. Figure 5 shows the curves of the surface potential versus bulk $\mathrm{pH}$ for pure $\mathrm{SiO}_{2}$ ISFETs and for $\mathrm{Si}_{3} \mathrm{~N}_{4}$ ISFETs. In each curve there are zones with higher and lower $\mathrm{pH}$ sensitivity. If the surface potential is shown versus the surface $\mathrm{pH}$, one can recognize a titration curve with two or three buffer zones, where the $\mathrm{pH}$ value equals the $\mathrm{pK}$ value of the different surface groups. These buffer zones represent the places, where a great amount of surface groups is available, which change their charge. This leads to a potential generation, which keeps the surface $\mathrm{pH}$ value nearly constant for these $\mathrm{pH}$

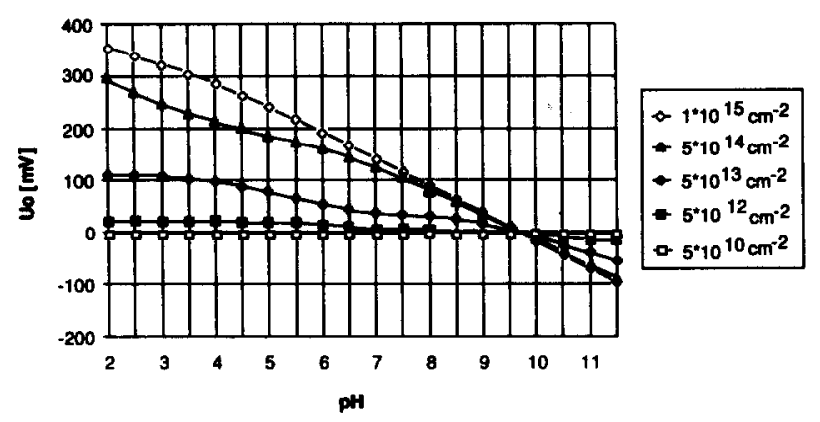

Fig. 4. Potential-pH curves for ISFETs with variable surface group density (ratio of amino:silanol groups 3:2).

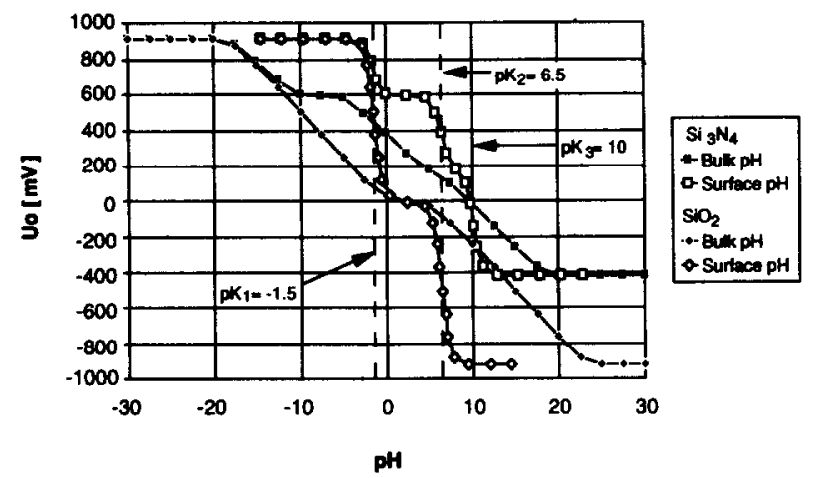

Fig. 5. Potential curves vs. surface- and bulk-pH for ISFETs with pure $\mathrm{SiO}_{2}$ and $\mathrm{Si}_{3} \mathrm{~N}_{4}$ gateinsulators. 


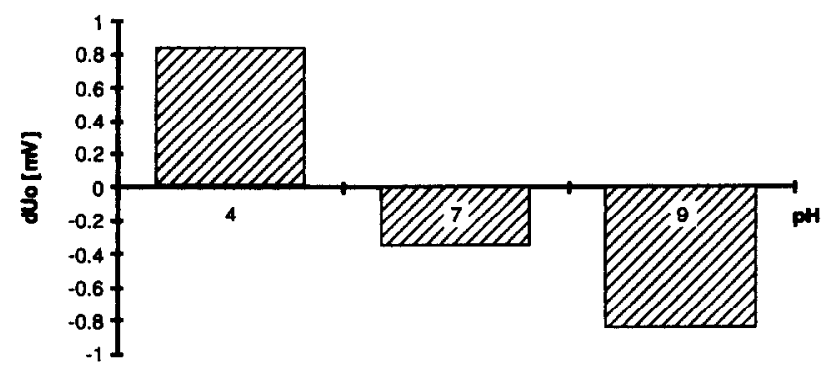

Fig. 6. Potential differences for good $\mathrm{pH}$ sensors with and without proteins (total surface group density $5 \times 10^{14} \mathrm{~cm}^{-2}$; protein density $\left.10^{12} \mathrm{~cm}^{-2}\right)$.

values. Therefore the potential generation at the surface is an important factor in the sensor reponse.

A very interesting result was obtained for the Immuno-FET. In spite of simple models, which assume the potential generation by proteins to be independent of the surface effects and therefore predict a strong response to the protein charge, according to our simulation there is only little response to the protein charges. Figure 6 shows the differences between a curve with and without protein charges for selected $\mathrm{pH}$ values. In a typical range between $\mathrm{pH} 4$ and 9 no potential difference greater than $1 \mathrm{mV}$ can be obtained. Even under the assumption of low ionic strength $\left(10^{-4} \mathrm{~mol} / \mathrm{l}\right)$ the potential difference will not exceed $10 \mathrm{mV}$. From the experimental side $10 \mathrm{mV}$ are near the lower detection limit for a dipstick sensor which is used in solutions with different $\mathrm{pH}$ and ionic strength values.

Additional simulations for an ISFET with reduced surface group density show that in this case the detection of protein charges seems to be feasible. Reduced surface group density means that the sensor is not pH-sensitive when carrying no proteins. The higher $\mathrm{pH}$ sensitivity for a sensor with a protein layer results from the $\mathrm{pH}$ dependence of the protein charges. Therefore the simulation suggests that an ISFET, which shows good pH sensitivity, cannot be used for the direct detection of protein charges, e.g., as an immuno-sensor. This result seems to explain why up to now no group has presented working direct immuno-FET.
As most of these groups work in the field of pH-ISFETs, their sensors are optimized for $\mathrm{pH}$ detection, which means that they possess a good $\mathrm{pH}$ sensitivity. Therefore the only way to create a direct immuno-sensor seems to consist in a degradation of the $\mathrm{pH}$ sensitivity, either by passivation [12] or the use of a new gateinsulator material. In this case, however, one will have to deal with an increased sensitivity of the sensor towards the concentration of the electrolyte ions. Thus the method of the static direct detection of protein charges will not lead to a commercial sensor within a short period of time.

\section{References}

1 J. Janata, An immunoelectrode, J. Am. Chem. Soc., 97(10) (1975) 2914.

2 L. K. Meixner, Untersuchungen zur Entwicklung eines Immunosensors auf Feld-Effekttransistor-Basis, Diploma Thesis, Technische Universität München, Germany, 1990.

3 D. E. Yates, S. Livine and T. W. Healy, Site-binding model of the electrial double layer at the oxide/water interface, J. Chem. Soc., Faraday Trans. I, 70 (1974) 1807-1818.

4 C. D. Fung, P. W. Cheung and W. H. Ko, A generalized theory of an electrolyte-insulator-semiconductor field-effect transistor, IEEE, ED-33(1) (1986) 8.

5 J. R. Sandifer, Theory of interfacial potential differences: effect of adsorption onto hydrated (gel) and nonhydrated surfaces, Anal. Chem., 60 (1988) 1553-1562.

6 P. Berg, Entwicklung einsatzfähiger Flüssigkeitssensoren auf Feldeffekttransistorbasis mit Hilfe eines speziellen CMOS-Technologie-Prozesses, Ph.D. Dissertation, Technische Universität München, Germany, 1989.

7 J. T. Edsall and J. Wayman, Biophysical Chemistry, Vol. I, Academic Press, New York, 1958.

8 D. L. Harame, L. J. Bousse, J. D. Shott and J. D. Meindl, Ion-sensitive devices with silicon nitride and borosilicate glass insulators, IEEE, ED-34(8) (1987) 1700.

9 A. Näbauer, Biosensoren auf der Basis von Feldeffekttransistoren, Ph.D. Dissertaion, Technische Universität München, Germany, 1988.

$10 \mathrm{P}$. Barabash, Static and dynamic models of electrolyte/insulator/ semiconductor field effect transistor, Ph.D. Dissertation, University of Toronto, Canada, 1987.

11 L. J. Bousse, The chemical sensitivity of electrolyte/insulator/ silicon structures, Ph.D. Dissertation, University of Twente, Netherlands.

12 H. Nakajima, M. Esashi and T. Matsuo, The cation concentration response of polymer gate ISFET, J. Electrochem. Soc., 129 (1982) 141. 